\title{
Malignant Melanomas Masquerade - As Benign Naevi
}

\author{
Maj T S Burge \\ FRCS, RAMC* \\ British Military Hospital, Hong Kong, BFPO 1
}

SUMMARY: Malignant melanoma is becoming more common. 'Curable' early, the prognosis worsens quickly with depth and stage.

Publicity in Hong Kong led to an increase in the referral and excision rates for 'benign' pigmented lesions. These excisions yielded $5 \%(3 / 61)$ malignant melanomas. It is suggested that aggressive policies of publicity and excision are justified, along with advice on prevention targeted at known high risk groups.

\section{Introduction}

In April 1988 a TV program, '60 Minutes Plus', was screened in Hong Kong. This Australian documentary described malignant melanoma as an epidemic. Following this screening there was a marked increase in the number of pigmented lesions referred to surgical outpatients. Unit policy meant that most of these lesions were excised although on clinical grounds none were thought to be malignant. The excisions were performed under local anaesthetic except in a small number of children.

Initially the patients gave, as their main reason for self referral, the TV program and subsequently the word of mouth spread of the news of the positive cases.

During this period several of the regular clinical meetings at BMH Hong Kong were concerned with this problem. These meetings were attended by members of all the service primary care practices in the colony.

\section{Findings}

During the period January-March 1988 no pigmented lesions were excised by the surgeons at BMH Hong Kong. In the subsequent 13 months (April 1988 - April 1989) 61 patients had pigmented lesions excised. None of these lesions were thought to be clinically malignant; however, three of them were found histologically to be malignant melanomas.

All the patients were European except for five Chinese and four Nepalese. Neither of the latter groups had any malignant cases. Among the Europeans the incidence was thus $5.8 \%$.

The three unsuspected cases of malignant melanoma are listed in Table 1. All were of the superficial spreading variety and Stage I.

Table 1

Patient details

\begin{tabular}{lllllll}
\hline $\begin{array}{l}\text { No. Age Sex Site } \\
\text { (Y) }\end{array}$ & $\begin{array}{l}\text { Depth } \\
\text { (mm) }\end{array}$ & $\begin{array}{l}\text { Time in } \\
\text { Far East (Y) }\end{array}$ & $\begin{array}{l}\text { Red hair/ } \\
\text { freckles }\end{array}$ \\
1 & 51 & F & Leg & 1.2 & 8 & No \\
2 & 39 & F & Arm & 1.0 & 15 & Yes \\
3 & 25 & M & Neck & 7.5 & 2.5 & Yes \\
\hline
\end{tabular}

\section{Discussion}

Malignant melanoma is increasing in incidence (1). It $\overrightarrow{\vec{\omega}}$ now accounts for $1-3 \%$ of all malignant tumours (2). Factors related to incidence include increasing age, decreasing latitude and caucasian race. Within the caucasian group hair/skin type is a major factor with red hair and pale freckled skin being the most vulnerable (3). It is generally accepted that these relationships reflect, in most cases, an aetiology involving increased ultraviolet (UV) exposure of those skin types least able to tolerate it. It is also suggested that (other than in lentigo maligna melanoma) the relationship is with the peaks of exposuge (as cause sunburn) rather than to lifetime cumulati朝 dose (4).

Aside from the UV damage model, some malignaAt melanomas appear to arise from pre-existing naevi. The exact relationship is unclear, but evidence of a pre-e\& isting naevus can be found in about $20 \%$ of maligna melanomas (5).

The features of a naevus which suggest maligna transformation are given in Table 2. Of these features colour variegation and border irregularity have been held to be the most diagnostically important (3).

Malignant melanomas may be divided into five $\overrightarrow{\vec{O}}$ clinical/histological subgroups:

Superficial spreading melanoma: this is the commonest type, making up about $64 \%$ of the total. They

Table 2

\section{Changes in a mole which suggest malignant} transformation

\begin{tabular}{ll}
\hline $\begin{array}{l}\text { Size } \\
\text { Outline }\end{array}$ & $\begin{array}{l}\text { - Enlargement } \\
\text { - Becomes irregular (indented and } \\
\text { notched) }\end{array}$ \\
Colour & - Becomes darker, then there is \\
& $\begin{array}{l}\text { irregularity of colour with various } \\
\text { shades of brown, pink etc }\end{array}$ \\
Elevation & - Becomes thicker and nodular \\
Surface & - Normal skin markings are lost \\
Surroundings & - Lumps in surrounding tissues \\
Symptoms & may be satellite tumours \\
& - Tingling, serous discharge and \\
& recurrent minor bleeding
\end{tabular}

* Now Honorary Registrar, Department of Cardio-Thoracic Surgery, Royal Infirmary of Edinburgh, Lauriston Place, Edinburgh, EH39YW 
are characterised by initial radial growth. They have, an irregular outline and intermittent itch is a common symptom. The prognosis is intermediate.

Nodular melanoma: this type accounts for about $28 \%$ of malignant melanomas. They have less of a radial growth phase than the superficial spreading type and they therefore present as a nodule rather than as a spreading mole. They may be 'amelanotic' although some pigment can usually be seen. Itch and bleeding occur frequently and ulceration occurs early. The prognosis is worse than in the superficial spreading type.

Lentigo maligna melanoma: unlike the other types they appear to be related to more chronic UV exposure. They arise within areas of lentigo maligna ('Hutchinsons melanotic freckle'), characteristically on the face of an elderly patient. Metastatic spread is rare and late. About $7 \%$ of malignant melanomas are of this type.

Acral lentiginous melanoma: these characteristically occur on the soles of the feet. The prognosis is poor.

Other melanomas: there are several other rare varieties which do not fit into any of the above groups. On the whole their prognosis is poor.

\section{Table 3}

\section{Staging for malignant melanoma (simplified)}

\begin{tabular}{ll}
\hline Stage I & Local disease \\
Stage II & Regional nodal involvement \\
Stage III & Disseminated disease
\end{tabular}

The prognosis in cases of malignant melanoma is firstly dependent on the stage of the tumour (Table 3 shows a simplified version of the staging system) (6). For Stage III disease the five year survival rate approximates to zero. For Stage II disease the five year survival rate is related to the number of involved nodes; a rate of $40 \%$ for one node falling to $15 \%$ for more than three nodes. Within Stage I disease the most important prognostic factor is the depth of the tumour. This is assessed in two ways:

Clark Level: the tumour invasion is related to the histological layers of the skin. This method has a high interobserver variation, but is usefully related to nodal spread (7).

Breslow thickness: the tumour invasion from the granular cell layer to the deepest layer of the tumour is measured in $\mathrm{mm}$. The ten year survival rates using this method are given in Table 4 (8).

\section{Table 4}

Prognosis of Stage I malignant melanoma according to tumour thickness

\begin{tabular}{ll}
\hline $\begin{array}{l}\text { Tumour thickness } \\
(\mathrm{mm})\end{array}$ & $\begin{array}{l}\mathbf{1 0} \text { year survival } \\
(\%)\end{array}$ \\
$<0.75$ & $98-99$ \\
$0.75-1.5$ & 90 \\
$1.5-3.0$ & 70 \\
$3.0-4.5$ & 60 \\
$>4.5$ & 30 \\
\hline
\end{tabular}

These cases support the view that all pigmented skin lesions excised must be sent for histology. In informal $\vec{z}$ communications many surgeons have mentioned similar $\_$ cases. This is particularly relevant in the NHS where the $?$ new GP contracts encourage GPs to perform such 'minor surgery' as the excision of skin lesions.

The high false negative rate would indicate that an $\overrightarrow{\vec{D}}$ aggressive policy of excision of pigmented lesions that cause any concern is justifiable. This rate should also be $\frac{\bar{\sigma}}{\sigma}$ compared with reported true positive rates of $3 \%$ in the $\overline{\bar{\omega}}$ UK (9) and $0.4 \%$ in the USA (10). Accurate clinical $\vec{\nabla}$ identification of malignant melanomas appears to be a difficult process.

Amongst this group $2 / 3$ were over $35,2 / 3$ had been in $\vec{\circ}$ the Far East over 5 years and $2 / 3$ were of the red haired $\vec{\overrightarrow{ }}$ and pale freckled skin type. Compared with the overall $\vec{\sigma}$ European patient base of BMH Hong Kong all of these factors appear to be significant, albeit in a very small sample. The index of suspicion in such patients should therefore be raised.

Publicity concerning malignant melanomas themselves has been shown to be useful previously and confirmed here $(9,10)$. On the basis that prevention is $\overrightarrow{0}$ better than cure, publicity also needs to be given to the 은 malignant risk of acute sun damage, particularly in oup few remaining 'sunshine postings'. The known high ris groups should be specifically targeted for advice. Pro tection, by modified behaviour, clothing, UV blockin creams etc. must be actively encouraged.

\section{REFERENCES}

1. Swerdlow A J. Epidemiology of cutaneous ma lignant melanoma. In: Mackie RM, ed. Clinics i⿳⺈. Oncology. Melanoma. Vol 3, No 3. Londor? Saunders 1984: 407-437.

2. EditORIAL. More on melanoma. Lancet 1985; 1: 201202.

3. Sober A J. Malignant melanoma. In: Fitzpatrick T P et al, eds. Dermatology in general medicine. New York: McGraw-Hill 1987: 947-949.

4. LeE J A H. Melanoma and exposure to sunlight. Epidemiol Rev 1982; 4: 110-136.

5. Adam $Y$ G, Efron G. Cutaneous malignant melanoma: current views on pathogenesis, diagnosis and surgical management. Surgery 1983; 93: 481494.

6. MACKIE R M, Young D. Human malignant melanoma. Int J Dermatol 1984; 23: 433-443.

7. MACKIE R M. Tumours of the skin. In: Rook A, Wilkinson D S, Ebling F J G, Champion $\mathrm{R} \mathrm{H}$, Burton J L, ed. Textbook of Dermatology. Oxford: Blackwell 1986: 2375-2487.

8. BREsLow A. Thickness, cross-sectional area and depth of invasion in the prognosis of cutaneous melanoma. Ann Surg 1970; 172: 902-908

9. Doherty V R, MAcKIE R M. Experience of a public education programme on early detection of $N$ cutaneous malignant melanoma. $\mathrm{Br}$ Med $J$ 1988; 297: 388-391.

10. Arundell F D. Screening for melanoma and skin $\mathrm{C}$ cancer. JAMA 1986; 255: 2443-2444. 